\title{
Variant Value Management to Optimize Complexity and Value of Product Families
}

\author{
Thomas Luft ${ }^{1}$, Christian Schmied ${ }^{2}$, Maximilian Schöberl ${ }^{2}$, \\ Sandro Wartzack ${ }^{3}$, Markus Zimmermann², Markus Mörtl² \\ ${ }^{1}$ J.M. Voith SE \& Co. KG, Heidenheim, Germany \\ ${ }^{2}$ Technical University of Munich, Germany; School of Engineering and Design, \\ Department of Mechanical Engineering \\ ${ }^{3}$ Friedrich-Alexander-Universität Erlangen-Nürnberg, Germany; Faculty of Engineering, \\ Department of Mechanical Engineering
}

\begin{abstract}
Increasing requirements lead to an evolutionary increase in complexity. As a result, direct and indirect costs also increase significantly, while value propositions for customers often stagnate. Hence, there are many interdependencies between complexity, costs and values. We present Variant Value Management (VVM) that systematically uses DSM-based interdependency analysis in the product portfolio to visualize the optimum between resource usage, customer value and generated complexity for each requirement, function and component of a product variant by means of target/actual cost comparisons of different product variants. Based on this, value-enhancing and value-destroying effects can be more specifically identified in current and future variant decisions for competitive and attractive product portfolios. The VVM was developed based on existing scientific approaches and in close cooperation with the technology company Voith and has already been successfully validated. The application of the VVM is demonstrated on the industrial case study of the Voith-Schneider Propeller (VSP).
\end{abstract}

Keywords: Variant management, value management, complexity management, industrial case study

\section{Introduction}

Developers are increasingly under pressure to integrate numerous functions into an existing product family due to heterogeneous specifications. In this way, companies expect their products to offer greater customer values and thus to be more competitive. However, the opposite is often the case. As a result of evolutionary, turbulent developments without a clear objective, product complexity and the associated complexity costs can increase without the realization of significant added value for customers and for companies.

Therefore, the main question, which is also the focus of the publication, is: How can the high external variance be realized with the lowest possible or value- and complexityoptimal internal variance? For this purpose, two methodologies are presented in this paper and integrated in the new Variant Value Management (VVM) approach, which aims to improve the described initial situation. In principle, this VVM approach requires the involvement of the responsible departments for development and design, value 
Thomas Luft, Christian Schmied, Maximilian Schöberl, Sandro Wartzack, Markus Zimmermann, Markus Mörtl

management, modularization, as well as product management and sales. The VVM approach should be implemented in early phases of product development, ideally during concept development. The focus is on product families where essential functions and working principles of the product variants are similar across the entire product family (e.g. modular product kits and series).

\section{State of the art and basic terminology}

In the section, important terms are defined, and two methodologies of value and complexity management are briefly described, their interrelationships are considered and, on this basis, the new VVM approach is presented by using the VSP as a case study. For literature, reference is made to the basic publications on value and cost management (e.g. Browning, 2003; Luft et al., 2014b; Mörtl and Schmied, 2015) and for variant and complexity management (e.g. Browning, 2016; Eppinger and Browning, 2012; Luft et al., 2013b; Luft and Wartzack, 2016; Schweigert et al., 2017).

\subsection{Definitions of terminology}

In this paper, a product is defined as a physical product (technical system) from the engineering industry, which in most cases is sold by a company to its customers (Ulrich et al., 2020). A product family is a selection of similar products developed on a common platform, each with particular functionality to meet specific customer requirements (Harlou, 2006; Meyer and Lehnerd, 1997). Modules are definable units, characterized by strong interrelations within the unit and few interrelationships between units (Baldwin, 2000). Variants are items of similar form or function with a usually high proportion of identical groups or parts. For a complete description of the variant, the hierarchical level should also be specified (e.g., product, module, or individual part variant).

A system consists of a set of elements (subsystems) that have properties and are linked by relationships or interdependencies. A system is delimited from its environment by a system boundary and is related to it by input and output variables (open system). Interdependencies are mutual dependencies and, in this paper, describe dependencies between autonomous elements, which can also be responsible for the creation of higherlevel system properties. An example is the joint fulfillment of a function by two components (i.e. physical parts of a product).

\subsection{Value Management Approaches}

Value management approaches (cf. Browning, 2003) aim to increase the value of a product and/or service, i.e., to minimize the resources used to meet customer needs and/or to meet customer needs more completely with available resources (see formula 1) (Miles, 2015; VDI, 2010).

Value $=\frac{\text { Fulfillment of customer needs and expectations }}{\text { Use of resources }} \quad$ Value $=\frac{\text { Functions }}{\text { Costs }}$

The most known approach is value management (also known as value engineering or analysis). The aim of value management is to increase the value of the product by reducing costs and increasing benefits. For this purpose, the functional model of a product is created 
according to a work plan to compare the values of the product with the corresponding costs of the product. In practice, this approach is mostly applied to existing products and therefore leads to subsequent change efforts. To avoid this, value management approaches have been developed to be applied in early phases of product development in order to consider and improve value in addition to cost already in the concept phase.

One such an approach is Integrated Value Engineering (IVE), which extends the functional model of value analysis and combines it with the target costing approach (Maisenbacher et al., 2013; Behncke et al., 2014; Maisenbacher, 2019): The product is modeled in three abstraction levels of requirements, functions, and components. Dependencies between the levels are recorded in matrix form and used to calculate target and actual costs for all system elements of these levels. The value ratio (formula 2) used for value design can be visualized in target cost control diagrams for a better overview at all levels. However, IVE does not cover variants, but highlights the need for research on it (Maisenbacher, 2019).

Value $($ system element $)=\frac{\text { Target costs }(\text { system element })}{\text { Actual costs }(\text { system element })}$

\subsection{Complexity management approaches}

Complexity indicates, among other things, the simultaneous occurrence of variety and variability. The management of variety is addressed in variant management. Variant management pursues the optimization of the dependency ratio of variety acting externally (external variance) to variety existing in the company (internal variance) and the handling of the effects of variety or - more comprehensively - complexity (formula 3) (compare Kersten, 2001; Menge, 2001).

Variety ratio $=\frac{\text { Diversity acting externally }(\text { variance external to the company })}{\text { Variety existing in the company }(\text { variance internal to the company })}$

Variety should be avoided as far as possible and/or at least reduced, since both internal and external variety increase complexity and thus the resources required to fulfill customer wishes and expectations. Complexity should exist only where it adds value for customers (Rebentisch et al., 2016). One possible approach to managing complexity, particularly in product development, is structural complexity management (Lindemann et al., 2009; Eppinger and Browning, 2012; Luft et al., 2014a). In this approach, the domains necessary to model the system, their elements, dependencies, and the level of abstraction are first identified. This system description is documented in a multiple domain matrix (MDM). In addition, information is collected to describe the direct system interrelations. These are expanded to include indirect system dependencies as far as they are useful for the system analysis. Then, the created system structure is analyzed to identify system properties that can be used to improve the product.

\subsection{Connection between value and complexity}

Many companies are aware of the challenge described in the introduction and counter it with improvement programs with the aim of establishing value management and complexity management during the development of new products and product variants. However, these two approaches are often applied in parallel and thus generate more effort 
Thomas Luft, Christian Schmied, Maximilian Schöberl, Sandro Wartzack, Markus Zimmermann, Markus Mörtl

on the one hand and fewer improvements and benefits on the other, which as a result often does not lead to sufficient success. Optimizing the value ratio and creating variants in all applications results in a higher degree of complexity in product families, which retroactively and with a time lag lowers the value ratio by requiring additional resources (Figure 1). The effects are difficult to quantify with existing methods. An integrated analysis of value ratio and complexity in the context of variants is necessary to be able to intervene in this cycle of effects in a way that improves rather than reinforces it.

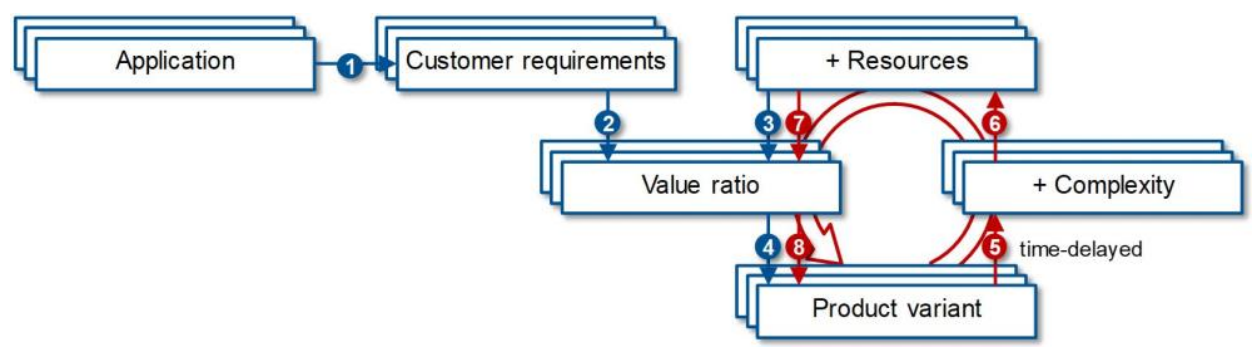

Figure 1: Connection between value ratio and complexity in a variant context

\section{Industrial case study using the example of Voith-Schneider Propeller}

The Voith-Schneider Propeller (VSP), named after both its promoting company Voith and its inventor Ernst Schneider, is a propulsion unit for ships which can generate thrust in all directions at any desired strength (see Jürgens and Fork, 2002, for details). The VSP consists of a rotating impeller with a vertical axis of rotation and several blades that are positioned on a circle parallel to the axis of rotation and project downward into the water from a wheel body that is flush with the bottom of the ship. The VSP is manufactured in small series and is a very material- and cost-intensive product. This case study focuses on the applications tugs (see Figure 2), ferries and offshore, each with an application-typical configuration of the VSP. The characteristics of the configurations are determined by an analysis of existing customer order data. This results in three typical VSP variants for these applications tugs, ferries and offshore. The configurations include, for example, different blade diameters (16 to $32 \mathrm{dm}$ ), different power ranges (540 to $2600 \mathrm{~kW}$ ), different control types (mechanical, electrical) and combinations of the design variants.

The VSP is used in different application scenarios and can meet a wide range of heterogeneous customer requirements. However, these requirements often have to be met in customer-specific development projects. This leads to increasing internal product and process complexity. The accompanying rising costs with relatively low unit volumes pose a challenge. The objectives of the case study can be broken down into the three functional areas of product management, value management and complexity management. In product management, the cooperation between sales and engineering is to be improved, for example through a common understanding of the product and the market. In Value Management, the aim is to determine the current value structure of the VSP variants in order to use this as a starting point for cost reductions and/or value increases. In complexity management, a market-oriented, modularized product structure is to be developed. 

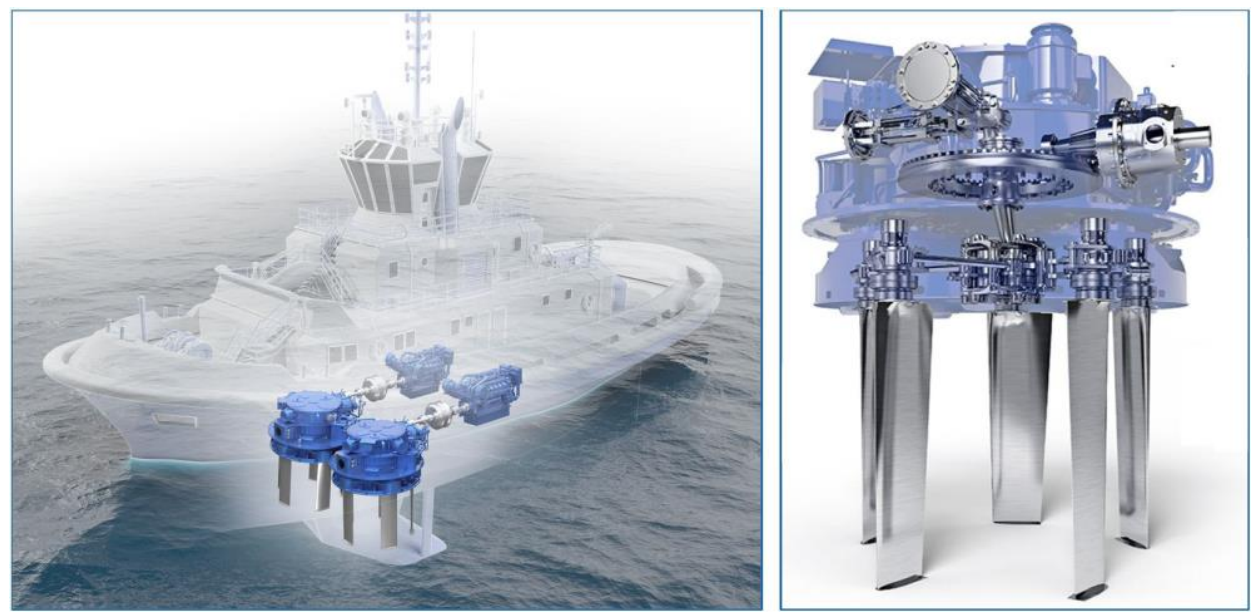

Figure 2: VSP pair in a tug (left), VSP (right), image source: Voith GmbH \& Co. KGaA

\section{Variant Value Management}

Based on the Integrated Value Engineering methodology (see section 2), the VVM approach presented in this paper provides a better consideration of interdependencies and can be used for both value management and complexity management. The approach has been developed directly from industrial practice and, thanks to its conceptual framework, can also be used for the iterative optimization of product portfolios. The methodological approach of the VVM approach consists of six steps (Figure 3).

The procedure starts with the modeling of the product. In the second step, the model is analyzed before it is subsequently evaluated in step three. In the fourth step, the evaluation is visualized for each product variant. Up to this point, the procedure is analogous to the Integrated Value Engineering procedure, but with consideration of all variants $\left(V_{1}-V_{n}\right)$. In the interpretation phase, a comparison of the different product variants is carried out in order to derive conclusions about the values of individual product variants and the product portfolio based on their interdependencies and discrepancies. These conclusions are used in the sixth step to make improvements to the product. These improvements can be validated by going through steps two to five again and then revised one more time in step six. In this way, an iterative optimization of the product and product portfolio is realized.

\subsection{Modeling}

The model that has to be created for the VSP includes the requirements, functions and component levels (see Table 1). First, a generic VSP Bill of Materials (BOM) is created based on BOMs of several VSP variants at the assembly level. If the number of assemblies is too large, the assemblies can be combined to form higher-level assemblies or only those assemblies can be considered that occur in each VSP variant (see exemplary section in Table 1). The assemblies are referred to as components in the following. 
Thomas Luft, Christian Schmied, Maximilian Schöberl, Sandro Wartzack, Markus Zimmermann, Markus Mörtl

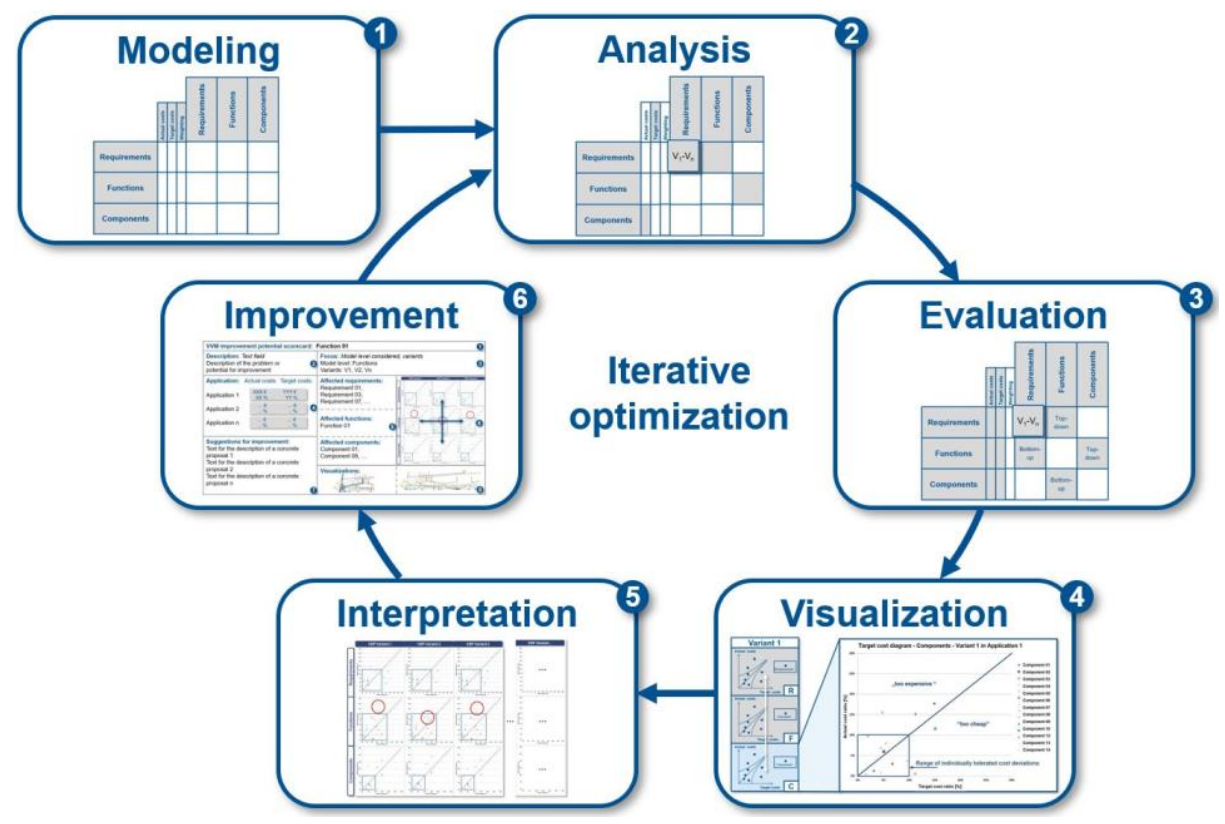

Figure 3: VVM for iterative optimization of variants in product families

On the basis of this generic BOM, the subtract-and-operate method (Feldhusen, 2016) is used in a workshop with developers to identify the basic functions of the VSP. In this process, the assembly under consideration is mentally taken from the functioning system in order to derive which functions are then no longer functioning. The component thus has a fulfilling part in these functions. In this way, 27 basic functions are identified, which are formulated in "noun + verb" style (see Table 1). To identify the requirements, eleven guided interviews are conducted with stakeholders from product management, service, development, sales and international independent sales agents (Luft and Wartzack, 2012).

Table 1: Modeling of the requirements, functions and components of the VSP

\begin{tabular}{|c|c|c|}
\hline Requirements & Functions & Components \\
\hline Operational reliability & $\begin{array}{c}\text { Transmit operating } \\
\text { information }\end{array}$ & Blade \\
\hline $\begin{array}{c}\text { Condition-independent } \\
\text { operation }\end{array}$ & Monitor operating status & Blade drive linkage \\
\hline Requirement 3 & Function 3 & Component 3 \\
\hline$\ldots$ & $\ldots$ & Component 14 \\
\hline Requirement 14 & Function 27 & \\
\hline
\end{tabular}

\subsection{Analysis}

In the second step, the analysis, the model parameters must be collected, put into context and quantified or evaluated quantitatively (see Figures 4 and 5). The most important input values in the VVM are the weightings of the requirements for each application considered or the respective variants $(1,3)$, the assigned total target costs (2) and the actual costs of 
the components (9), as well as proportionally/percentage quantified dependencies between components and functions and functions and requirements $(5,7,10,12)$. The target costs (2) in this case study are determined via a total cost of ownership consideration of the VSP in an appropriate application versus a competitor product (i.e., out-of-competitor), and the relative result is applied to the other applications. The actual costs (9) of the components/ assemblies are derived from generic bills of materials, which are also used by Sales to prepare offers. The requirements must be weighted in all applications to consider the different customer requirements of different application cases (Figure 4). The weightings are the result of pairwise comparisons (1) carried out by several sales staff for the different markets of tugs, ferries, offshore.
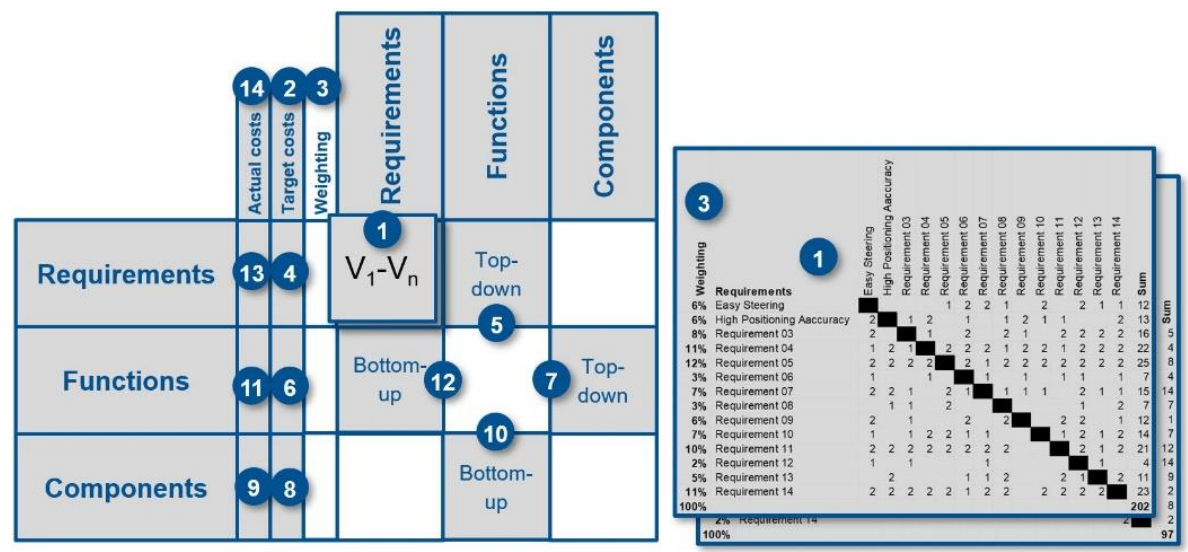

Figure 4: Weighting of requirements (to be done for each application/variant separately)

The relations between components and functions are known qualitatively via the subtractand-operate method performed in step 1 . These must also be quantified quantitatively. For this purpose, the qualitative relations in the case study are processed in a componentfunction-requirements model, which was also visualized with the graph-based software Soley (Figure 5), which is suitable for visualizing MDMs (Schweigert et al., 2017).

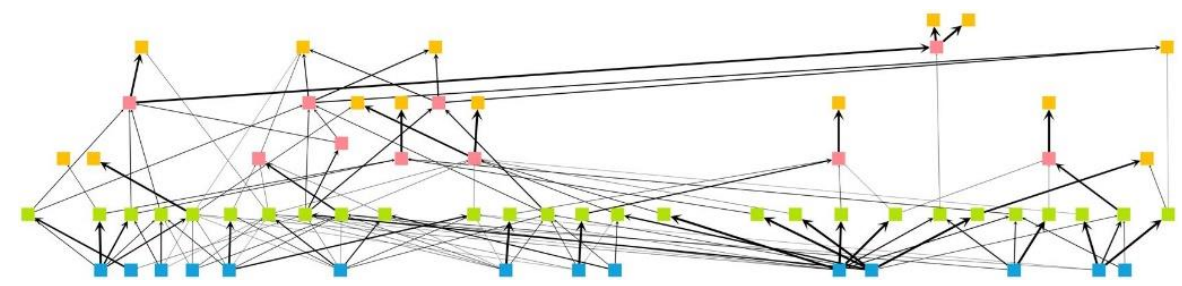

Figure 5: Integrated, weighted functional graph-based model of the VSP (from top to bottom: orange $=$ requirements, red $=$ main functions, green $=$ functions, blue $=$ components $)$

In a workshop, each function is discussed separately with the developers in order to allocate the function fulfillment $(100 \%)$ to the fulfilling components. This procedure results in the top-down relationship (7) between function and component (function is fulfilled by component). For the bottom-up relationship (10), the matrix (7) is transposed and the 
Thomas Luft, Christian Schmied, Maximilian Schöberl, Sandro Wartzack, Markus Zimmermann, Markus Mörtl

values are normalized to the column sum (sum per component) (see also the corresponding Excel template in Figure 6).

To determine the function-requirement relationships, the functions included in the model are abstracted. The resulting higher-level functions are assigned to the requirements and this assignment is then weighted top-down (5). To calculate the bottom-up weighting, transpose as for the component-function relationships and normalize to the row sum (12).

\subsection{Evaluation}

In the following step, the prior results are combined in an Excel template and mathematically evaluated. Figure 6 shows the calculation path for the target costs (blue, $2-$ 8 according to top-down) and the actual costs (green, 9-13 according to bottom-up). The total target costs (2) are broken down to the individual requirements by multiplication with the weights of the requirements (3). In the next step, the target cost vector (4) of the requirements is multiplied by the requirements-functions matrix (5) to determine the target cost per function (6). The target cost vector of the functions is then multiplied by the functions-components matrix (7) to give the target cost vector of the components (8).

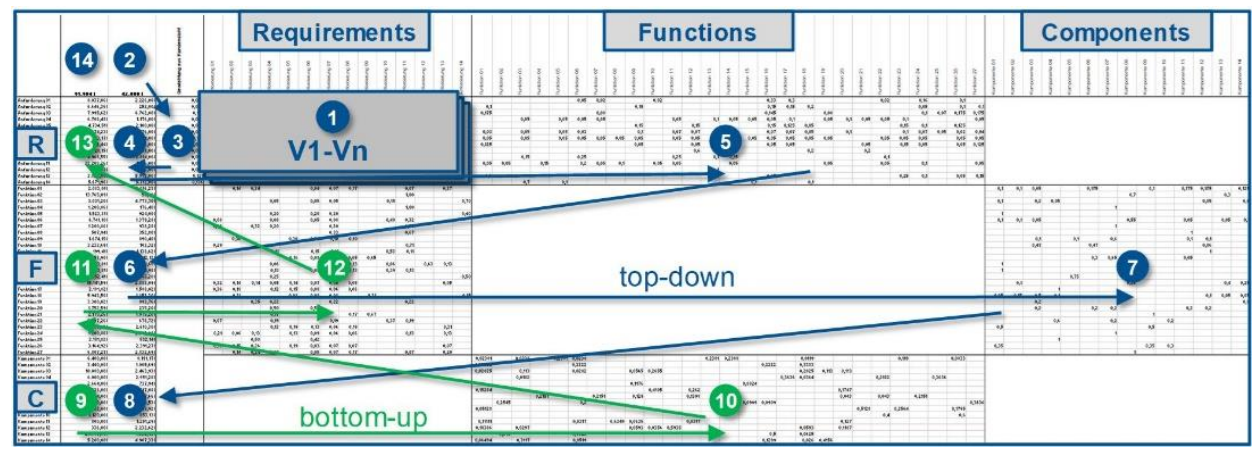

Figure 6: Extract of the Excel template for the VVM calculations for each variant

The same procedure is used to determine the actual costs. A breakdown of the actual costs to an actual cost vector is not necessary if the actual costs are already available per component (9). This is multiplied by the component function matrix (10) to calculate the actual cost vector of the functions (11). Afterwards, the functions actual cost vector is multiplied by the function requirements matrix (12) to give the requirements actual cost vector (13). The total actual costs (14) are the component actual costs summed from (9). The VVM Excel template used is available from the authors on request.

\subsection{Visualization}

For visualization, target cost diagrams of the cell ranges (13/4), (11/6), (9/8) from Figure 6 for requirements, functions and components are derived one variant each (see Figure 7). This clearly shows the vertical interdependencies between the model levels. The range of individually tolerated cost deviations was represented simplifying as square in the diagram. All points (requirements, functions or components) outside this range were considered for value optimizations. 


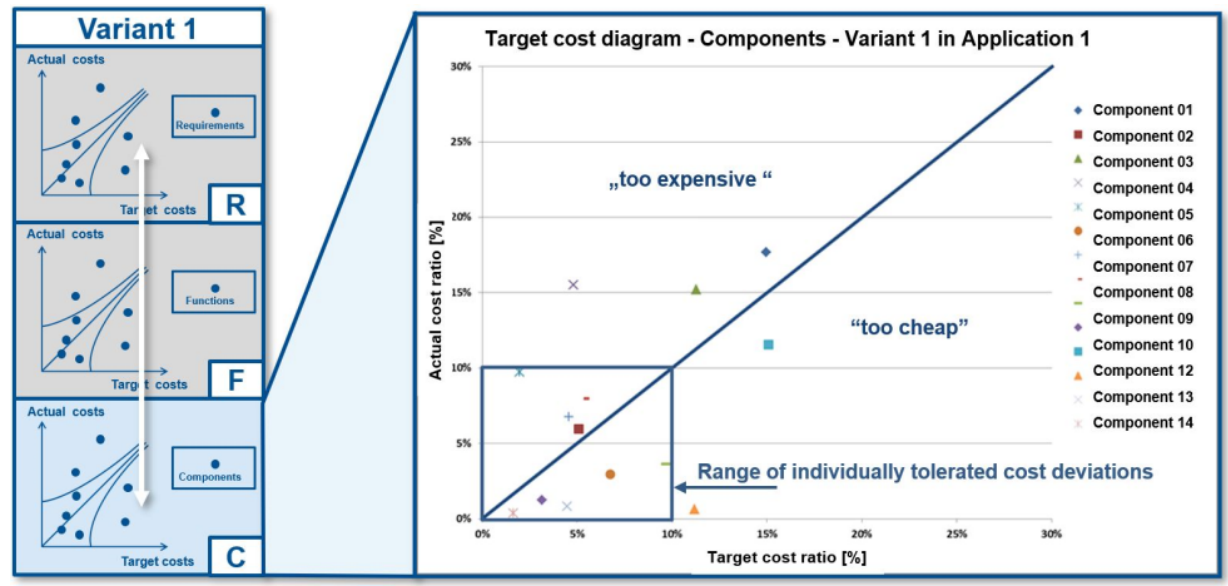

Figure 7: Target cost control diagram of the components of the VSP, variant 1, in application 1

\subsection{Interpretation}

In order to compare different variants (horizontal interdependencies), the visualizations of the individual variants are placed next to each other (1-n). For this purpose, instead of absolute actual and target costs, shares normalized to the respective sum are used. In addition, the same maximum value is assigned to the axes, resulting in quadratic target/actual cost diagrams. In order to increase comparability, uniform maximum values are also defined for each model level. The resulting Variant Value Management Matrix (VVMM) is shown in Figure 8.

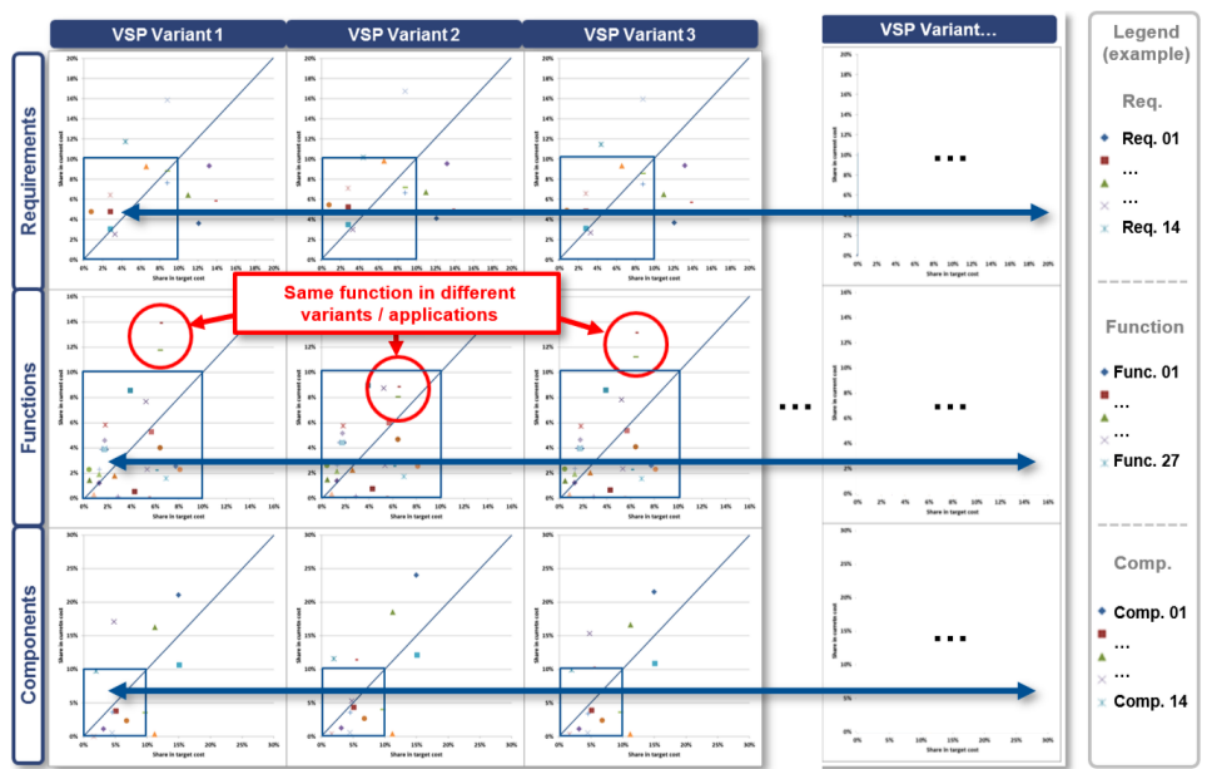

Figure 8: Variant Value Management Matrix for variant comparison 
Thomas Luft, Christian Schmied, Maximilian Schöberl, Sandro Wartzack, Markus Zimmermann, Markus Mörtl

\subsection{Improvement}

The new approach enables an interpretation across variants. Actual/target costs of requirements, functions and components can be different in variants. The red circles in Figure 8, for example, mark the same function in different variants. In the VSP case study, some deviation points arose which could be examined more closely, questioned and then optimized. For each deviation identified in the interpretation step, specific suggestions for improvement can be developed. In the case of the VSP, a number of helpful improvement potentials were identified for requirements, functions and components, which were then examined in more detail in the context of the variants. The developed systematic VVM improvement potential scorecard (see Figure 9) proved to be helpful.

Field (1) of the VVM improvement potential scorecard names the identified potential item (e.g. function 1). Field (2) describes the improvement potential or problem in order to create a uniform and clear understanding for everyone in the interdisciplinary team. Field (3) identifies the model level being considered and also which variant(s) in which application. Field (4) provides the comparison of target and actual costs in each application. Field (5) shows the vertical interdependencies across the affected elements of the model levels. In addition to the text-based description, field (5) can also be used to display the affected requirements and components as a graph-based detail section and also as an overall representation (field 8). Field (6) displays the VVM matrix as a visual comparison basis of the individual points for horizontal interdependencies across variants. Field (7) shows the core area of improvements and innovations that can be worked out in the environment of potentials, target/actual cost comparisons and interdependencies to surrounding variants (field 6) and interdependencies to model levels (field 5). To increase the value of the VSP offer, some improvements from the considered potentials are then implemented: electrification, power concentration, revised configuration space, improved variant and module definition.

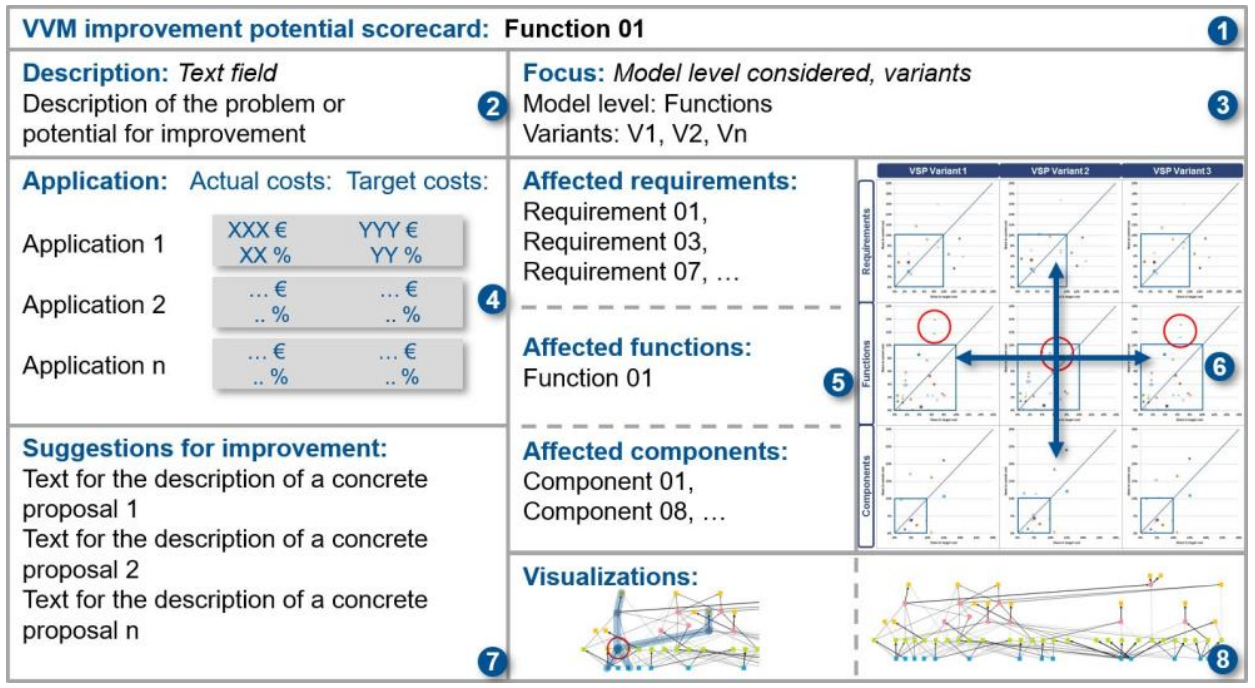

Figure 9: VVM improvement potential scorecard to optimize the product portfolio 


\section{Conclusions}

\subsection{Discussion}

As shown in the industrial case study, the VVM procedure for improving variants in the existing product portfolio, can also be run through for further iterations to compare and evaluate new variants. For this purpose, variants in one application, variants in several application areas (in the case of VSP, e.g. for tugs, ferries, offshore) or variants in new markets and application areas can be considered. Interesting results in the VSP example are that some components differed greatly in target costs and thus in customer expectations in the three applications tugs, ferry and offshore. With this information, specific variants/modules could be defined for the applications and where components did not have different requirements in the different application fields, a uniform design makes sense. Overall, the adaptation effort for designs per order is thus reduced, and further annually effective value improvements are successfully created. In terms of time, the application of the VVM in the case study had an effort in the order of 80 hours in total, which is comparable to other methods of value analysis.

\subsection{Conclusions}

The new MDM/IVE-based VVM approach supports to optimize complexity and value of product families, which has not been sufficiently solved in research and practice so far (Maisenbacher, 2019). The VVM approach has successfully evaluated by using VSP in an industrial case study. The approach can be applied both to the optimization of existing product portfolios and to the design of new variants. By analyzing the interdependencies between requirements, functions and components, as well as the different application areas of the variants, the mutual influence of value and complexity can be positively resolved and used to increase value.

\subsection{Outlook}

The VVM can also be applied to other products. Voith has already successfully applied it to a bus transmission. The Excel template with integrated generic interfaces also to free graph visualization programs (e.g. Gephi, NodeXL) makes it easier for interested parties to use it. For future market tightening, the approach can be further developed by opening up to deeper analysis, e.g. indirect interdependency effect chains (Schmied et al., 2015). In addition, the matrix based VVM can also be supplemented with other domains, such as process, people and information domains (see Luft et al., 2013a).

\section{References}

Baldwin, C. Y., Clark, K. B.: Design Rules - The Power of Modularity. MIT Press 2000

Behncke, F. G.; Maisenbacher, S.; Maurer, M.: Extended Model for Integrated Value Engineering. Procedia Computer Science 28 (2014), pp. 781-788

Browning, T. R.: Design Structure Matrix Extensions and Innovations: A Survey and New Opportunities. IEEE Transactions on Engineering Management 63 (2016) 1, pp. $27-52$.

Browning, T. R.: On Customer Value and Improvement in Product Development Processes. Systems Engineering 6 (2003) 1, pp. 49-61

Eppinger, S. D.; Browning, T. R.: Design Structure Matrix Methods and Applications. Cambridge: MIT Press 2012 
Thomas Luft, Christian Schmied, Maximilian Schöberl, Sandro Wartzack, Markus Zimmermann, Markus Mörtl

Feldhusen, J.: Funktionsmodellierung. In: Lindemann, U.: Handbuch Produktentwicklung. München: Hanser 2016, p. 995

Harlou, U.: Developing Product Families Based on Architectures: Contribution to a Theory of Product Families. TU Denmark, Diss. 2006

Jürgens, B.; Fork, W.: Faszination Voith-Schneider-Propeller. Hamburg: Koehler 2002

Kersten, W.: Vielfaltsmanagement. München: TCW 2001

Lindemann, U.; Maurer, M.; Braun, T.: Structural Complexity Management. An Approach for the Field of Product Design. Berlin: Springer 2009

Luft, T.; Bochmann, J.; Wartzack, S. (2013a): Enhancing the Flow of Information in the PLM by Using Numerical DSMs - An Industrial Case Study. IFIP Advances in Information and Communication Technology 409 (2013), pp. 90-99

Luft, T.; Ewringmann, N.; Wartzack, S. (2014a): Application and Validation of the Matrix-based Product Description in a Case Study by Using the Software Loomeo. Procedia CIRP 21 (2014), pp. 479-484

Luft, T.; Klein, F.; Wartzack, S. (2014b): Weight and Cost Reduction of the Thermal Management for Traction Batteries by Using the DSM Methodology. Dubrovnik: Design Conference 2014

Luft, T.; Krehmer, H.; Wartzack, S. (2013b): An advanced procedure model for property-based product development. Seoul: International Conference on Engineering Design 2013

Luft, T.; Wartzack, S.: Application, Evaluation and Future Research Potential of the Matrix- and Graph-based Product Model. Dubrovnik: Design Conference 2016

Luft, T.; Wartzack, S.: Requirement analysis for contextual management and supply of process and design knowledge - a case study. Dubrovnik: Design Conference 2012

Maisenbacher, S.: Integrated Value Engineering. Leitfaden zur integrierten Betrachtung von Produktwerten. TU München, Diss. 2019

Maisenbacher, S.; Behncke, F.; Lindemann, U.: Model for Integrated Value Engineering. Bangkok: IEEE Industrial Engineering and Engineering Management 2013

Menge, M.: Ein Beitrag zur Beherrschung der Variantenvielfalt in der auftragsbezogenen Einzel- und Kleinserienfertigung komplexer Produkte. TU Braunschweig, Diss. 2001

Meyer, M.; Lehnerd, A. P.: The Power of Product Platforms. Building Value and Cost Leadership. New York: The Free Press 1997

Miles, L. D.: Techniques of Value Analysis and Engineering. Newark: Miles Value Foundation 2015

Mörtl, M.; Schmied, C.: Design for Cost - A Review of Methods, Tools and Research Directions. Journal of the Indian Institute of Science, 95 (2015) 4, pp. 379-404

Rebentisch, E.; Schuh, G.; Riesener, M.; Gerlach, M.; Zeller, P.: Determination of a Customer Valueoriented Product Portfolio. Procedia CIRP 50 (2016), pp. 82-87

Schweigert, S.; Luft, T.; Wartzack, S.; Lindemann, U.: Combination of Matrix-based and Graphbased Modeling for Product and Organizational Structures. Espoo, Finland: Inter-national Dependency and Structure Modeling Conference 2017

Schmied, C.; Reinbold, G.; Amekrane, R.; Igenbergs, E.; Mörtl, M.; Lindemann, U.: Extended Cost Analysis with Systems Engineering Considerations. INCOSE/GfSE Tag des Systems Engineering. München: Hanser 2015, pp. 227-236

Ulrich, K. T.; Eppinger, S. D.; Yang, M. C.: Product Design and Development. New York: McGrawHill 2020

VDI Richtlinie 2800:2010-08: Wertanalyse. Berlin: Beuth 2010

Contact: Thomas Luft, J.M. Voith SE \& Co. KG, Heidenheim, Alexanderstraße 2, 89522 Heidenheim, Germany, Phone+49 732137 8471, thomas.luft@ voith.com 